\title{
APROXIMAÇÕES ENTRE UNIVERSIDADE E ESCOLA: \\ RACISMO EM DISCUSSÃO
}

\section{APPROACHES BETWEEN UNIVERSITY AND SCHOOL: RACISM IN DISCUSSION}

\author{
Michele Pereira de Souza da Fonseca ${ }^{17}$ \\ Mariana Peres ${ }^{18}$ \\ Raquel Ludovino ${ }^{19}$ \\ Carina Freire ${ }^{20}$
}

\begin{abstract}
Resumo
Este artigo tem por objetivo analisar as experiências do $7^{\circ}$ Ciclo de Cinema e Diversidade, em duas Escolas Municipais do Rio de Janeiro, uma localizada na Zona Norte e outra na Zona Sul da cidade, em turmas do 8o e 9o ano, com o tema Racismo. Apoiando-se numa perspectiva ampla da inclusão, baseamos esta ação extensionista na reflexão sobre assuntos atuais que são negligenciados, mas que devem ser abordados de maneira dialógica nas escolas. A partir dos relatos dos estudantes, percebemos que a luta coletiva por uma educação antirracista é fundamental e só será efetivada se, no lugar de silenciamentos, omissões, opressões e dores, promovermos ações pedagógicas inclusivas, reflexivas e participativas, para que os privilégios sejam repensados e os preconceitos sejam eliminados.
\end{abstract}

Palavras-chave: Inclusão. Extensão. Universidade. Escola.

\section{Abstract}

This article aims to analyze the experiences of the 7th Cycle of Cinema and Diversity, in two Municipal Schools in Rio de Janeiro, one located in the North Zone and the other in the South Zone of the city, in classes of the 8th and 9th grade, with the theme Racism. Considering a broad perspective of inclusion, we base this extensionist action on the reflection on current issues that are neglected, but which must be addressed in a dialogical

\footnotetext{
17 Doutora em Educação (PPGE/UFRJ), Mestre em Educação (PPGE/UFRJ), Licenciada em Educação Física (EEFD/UFRJ). Professora adjunta da Escola de Educação Física e Desportos da Universidade Federal do Rio de Janeiro (EEFD-UFRJ). Coordenadora de Extensão da EEFD-UFRJ. Fundadora e Coordenadora do LEPIDEFE Laboratório de Estudos e Pesquisas sobre Inclusão e Diferenças na Educação Física Escolar (EEFD-UFRJ). Coordenadora da Pós-Graduação gratuita em Educação Física Escolar na Perspectiva Inclusiva (UFRJ). Membro do Comitê Científico GTT Inclusão e Diferenças do Colégio Brasileiro de Ciências do Esporte (CBCE). E-mail: michelepsf22@gmail.com. ORCID: https://orcid.org/0000-0003-0355-2524

18 Licencianda em Educação Física da Escola de Educação Física e Desportos da Universidade Federal do Rio de Janeiro (EEFD-UFRJ). Integrante do LEPIDEFE - Laboratório de Estudos e Pesquisas sobre Inclusão e Diferenças na Educação Física Escolar (EEFD-UFRJ). E-mail: marianaperes@ufrj.br. ORCID: https://orcid.org/0000-0001-7585-8026

19 Licencianda em Educação Física da Escola de Educação Física e Desportos da Universidade Federal do Rio de Janeiro (EEFD-UFRJ). Estudante do LEPIDEFE - Laboratório de Estudos e Pesquisas sobre Inclusão e Diferenças na Educação Física Escolar (EEFD-UFRJ). E-mail: ludovino91@gmail.com. ORCID: https://orcid.org/0000-0001-9077-981X

${ }^{20}$ Pós Graduanda em Ênfase em Educação Física Escolar (CESPEB/UFRJ), Licenciada em Educação Física pela Escola de Educação Física e desportos da Universidade Federal do Rio de Janeiro (EEFD-UFRJ). Integrante do LEPIDEFE - Laboratório de Estudos e Pesquisas sobre Inclusão e Diferenças na Educação Física Escolar (EEFDUFRJ). E-mail: carinamillen@gmail.com. ORCID: https://orcid.org/0000-0001-6382-5251
} 


\section{RevistAleph}

way in schools. From the students reports, we realize that the collective struggle for an antirracist education is fundamental and will only be effective if, instead of silencing, omissions, oppression and pain, we promote inclusive, reflective and participatory pedagogical actions, so that privileges are rethought and preconceptions are eliminated. Keywords: Inclusion. Extension. University. School.

\section{Introdução}

A escola pública que desejo é a escola onde tem lugar de destaque a apreensão crítica do conhecimento significativo através da relação dialógica (FREIRE, 2001, p.83).

Inspiradas por Paulo Freire (2001), acreditamos que a escola é o espaço do incentivo ao questionamento, a crítica, a criação, a proposição, ao diálogo, a construção coletiva e participativa, "articulando o saber popular e o saber crítico, científico, mediados pelas experiências do mundo". (p.83). A extensão é parte da base da vida universitária e parte do princípio constitucional da indissociabilidade entre ensino, pesquisa e extensão, conceituada como "um processo interdisciplinar educativo, cultural, científico e político que promove a interação transformadora entre universidade e outros setores da sociedade (FORPROEX, 2012, p. 42).

A indissociabilidade entre ensino, pesquisa e extensão compõe as diretrizes de extensão universitária (FORPROEX, 2012), juntamente com a interação dialógica; interdisciplinaridade e interprofissionalidade; impacto na formação do estudante e impacto e transformação social, que visa promover uma interação que transforma não apenas a Universidade, mas também os setores sociais com os quais ela interage.

Baseada nos princípios de Paulo Freire (1992), a extensão, especialmente nas universidades públicas brasileiras, busca se configurar como uma ação institucional que promove troca de saberes acadêmicos e populares, se distanciando sobremaneira da ideia de transferir ou depositar verticalmente o conhecimento de modo mecanicista, posto que "O conhecimento não se estende do que se julga sabedor até aqueles que se julga não saberem; o conhecimento se constitui nas relações homem-mundo, relações de transformação, e se aperfeiçoa na problematização crítica destas relações" (FREIRE, 2006, p. 36). 


\section{RevistAleph}

De acordo com Nogueira (2005, p. 51), as camadas populares deixaram de ser o objeto e passaram a ser sujeitos ativos da ação extensionista. Assim, a Extensão visa:

[...] implementar o processo de democratização do conhecimento acadêmico, estabelecer mecanismos de integração entre os saberes acadêmico e popular, de forma que a produção do conhecimento se efetive no confronto com a realidade, com permanente interação entre teoria e prática.

A extensão pode promover o 'desencastelamento' da universidade, no sentido de avançar na via de conhecimento de múltiplas mãos, considerando a realidade social que a circunda, por meio de ações educativas para o fortalecimento do pensamento reflexivo, crítico e autônomo, fazendo sentido para a formação acadêmica e humana nesta complexa conjuntura contemporânea que vivemos.

Nesse sentido, temos considerado nas ações extensionistas desenvolvidas pelo LEPIDEFE (Laboratório de estudos e pesquisas sobre inclusão e diferenças na Educação Física escolar), vinculado à Escola de Educação Física e Desportos da Universidade Federal do Rio de Janeiro (EEFD-UFRJ), a relevância da valorização e proposição do diálogo estreito entre universidade e sociedade, mais especificamente a universidade e a escola.

Considerando nossa área de atuação, esta tem sido uma preocupação constante. A Educação Física possui marcas de um histórico excludente (SILVA, 2004), de enaltecimento do rendimento físico e performance, porém contemporaneamente tem sido ressignificada numa perspectiva inclusiva atendendo as peculiaridades e diferenças de cada um (FONSECA, 2014). Para isso, nos embasamos num conceito de inclusão amplo, dialético, processual e infindável (SAWAIA, 2017; SANTOS, FONSECA E MELO, 2009; BOOTH e AINSCOW, 2012) considerando amplamente todas as singularidades humanas em seus complexos processos de inclusão/exclusão como questões de gênero, relações étnicoraciais, classe social, religiosidade, deficiências e outras tantas.

Nesse sentido, como instrumento potencializador de reflexões a respeito dos marcadores sociais, o Ciclo de Cinema e Diversidade, ligado ao Projeto de Extensão Educação Física escolar na perspectiva inclusiva, é um evento de extensão que acontece anualmente e tem por objetivo propiciar debates acerca das questões relacionadas às diferenças humanas em uma perspectiva dialética que considere os processos inclusivos e excludentes na Educação Física escolar, tendo o cinema como inspiração dessas reflexões coletivas. 


\section{RevistAleph}

Tal debate é desencadeado com a exibição de filmes que se aproximam da temática em tela. Os temas de cada ciclo são selecionados por meio das discussões dos integrantes do LEPIDEFE a partir das demandas percebidas no decorrer das práticas dos licenciandos durante o projeto de extensão.

Esse evento, efetivado a partir da organização parceira dos grupos LEPIDEFE (Laboratório de estudos e pesquisas sobre inclusão e diferenças na educação física escolar) e ESQUINA - Cidade, Lazer e Animação Cultural, vinculados à Escola de Educação Física e Desportos da Universidade Federal do Rio de Janeiro (EEFD-UFRJ), foi criado no ano de 2013, ocorrendo apenas na universidade (EEFD-UFRJ), convidando a comunidade externa para participar da exibição e das discussões a partir dos filmes cuidadosamente escolhidos $^{21}$.

A partir de 2017, reconfiguramos o evento que também passou a acontecer nas escolas públicas parceiras, com participação mais ativa do público-alvo por meio de dinâmicas e debates após a exibição do filme ${ }^{22}$. Assim, desde então, o evento de extensão acontece anualmente em duas Escolas Municipais e na EEFD-UFRJ.

Para isso, considerou-se a amplitude do conceito de inclusão e a necessidade de discutir e refletir questões sobre deficiência, gênero, raça e etnia, fracasso escolar ou quaisquer outros fatores excludentes e que também tem desdobramentos na Educação Física Escolar.

O presente artigo tem por objetivo analisar a experiência do $7^{\circ}$ Ciclo de Cinema e Diversidade ocorrido em 2019, em duas Escolas Municipais do Rio de Janeiro, uma localizada na Zona Norte e outra localizada na Zona Sul da cidade, em turmas do 8o e 9응 ano, com o tema Racismo. A realização deste evento de extensão objetiva trazer a reflexão sobre assuntos atuais que são negligenciados, mas que devem ser abordados nas escolas e podem ser realizados por meio de múltiplas linguagens.

\footnotetext{
21 1o Ciclo de cinema e diversidade: a escola em foco (2013). Filmes: Como Estrelas na Terra, Toda Criança é Especial; Saindo do armário; Vermelho como o céu; Preciosa.

20 Ciclo de cinema e diversidade: amizade (2014). Filmes: Colegas; As vantagens de ser invisível; Tomboy; Intocáveis.

3o Ciclo de cinema e diversidade: relações étnico-raciais (2015). Filmes: Quanto Vale ou é por Quilo?; Promessas de um Novo Mundo; Quase Deuses; Babel.

4을 Ciclo de cinema e diversidade: sexualidade (2016). Filmes: Hasta la Vista; A massai branca; Gerontophilia e O clube.

22 5o Ciclo de cinema e diversidade: deficiências (2017). Filmes: O milagre de Anne Sullivan; Todos com todos. 60 Ciclo de cinema e diversidade: bullying (2018). Filmes: Aos teus olhos; Cyberbully (Bullying virtual).

7을 Ciclo de cinema e diversidade: racismo (2019). Filmes: Corra!; Ninguém nasce assim.
} 


\section{RevistAleph}

A partir das reuniões do LEPIDEFE, ocorreu a escolha do tema racismo, atendendo as demandas das próprias escolas e por ser um dos focos de nossos estudos e discussões na perspectiva inclusiva. Munanga (2012, p. 10) aponta que o "afastamento e a destruição da consciência histórica era uma das estratégias utilizadas pela escravidão e colonização, para destruir a memória coletiva dos povos escravizados e colonizados". Acreditamos que a educação precisa se comprometer em reverter as sequelas decorrentes de mais de 300 anos de escravidão desenvolvendo ações pedagógicas habituais não só em momentos pontuais mas ao longo da trajetória escolar e formativa dos estudantes. Como parte das ações cotidianas do PEFEPI temos essa preocupação e este evento de extensão ressalta mais uma vez esta importância.

\section{Caminhos metodológicos}

A partir da escolha do tema no evento, realizamos um levantamento a respeito de filmes, curtas-metragens ou documentários que dialogassem com o tema. Uma dinâmica também foi pensada a partir do tema de modo a potencializar o debate após a exibição do filme.

O filme escolhido se trata do documentário intitulado "Ninguém Nasce Assim ${ }^{23 ",}$ com duração de aproximadamente 29 minutos. Este, produzido em 2014 pela Equipe de História do Colégio Pedro II, localizado no bairro Humaitá, no Rio de Janeiro, relata um caso de racismo cometido pelos próprios estudantes do colégio, durante um jogo de futebol que aconteceu no intervalo das aulas.

O documentário, organizado pelo professor de história Cristiano Campos (direção, roteiro, filmagem e edição), traz os pontos de vista de vários atores sociais na instituição envolvida. Um fator determinante para a escolha desse documentário foi por apresentar a percepção dos estudantes do colégio sobre o ocorrido, pois a linguagem e o ambiente aproximaria os estudantes que o assistissem, tendo em vista que também seriam de escola pública e de faixa etária semelhante.

Metodologicamente, a pesquisa-ação embasa nossas ações tanto no projeto quanto no evento de extensão no sentido de ampliar e explicitar a interação entre

\footnotetext{
${ }^{23}$ Disponível em: https://www.youtube.com/watch?v=6H xfUCLWBY\&t=12s
} 


\section{RevistAleph}

pesquisadores e pessoas da situação estudada, envolvidos de modo cooperativo e participativo (THIOLLENT, 2000).

Participaram 139 estudantes de 8 ㅇ e 9으 ano, de duas escolas municipais situadas, respectivamente, na zona norte (Jardim Guanabara - Ilha do Governador) e na zona sul (Leblon) do Rio de Janeiro, com idade entre 14 e 16 anos. As duas escolas não estão localizadas fisicamente dentro de favela, pelo contrário, ambas estão situadas em bairros economicamente valorizados, porém recebem muitos estudantes moradores das favelas do entorno. Também estavam presentes as professoras de educação física das escolas, bem como outros docentes interessados em participar do evento.

Antes de iniciar a exibição do documentário "Ninguém nasce assim", apresentamos a sinopse e uma breve contextualização do tema. Após a exibição, incentivamos a formação de pequenos grupos para realização da dinâmica. Em todos os grupos havia um mediador integrante do LEPIDEFE, assim, utilizamos a metodologia do grupo focal, que para Gatti $(2005$, p.9) "permite fazer emergir uma multiplicidade de pontos de vista e processos emocionais, pelo próprio contexto interação criado, permitindo a captação de significados que, com outros meios poderiam ser difíceis em manifestações."

A dinâmica pensada, e ressignificada coletivamente, consistiu, em um primeiro momento, na exibição de características de 11 personalidades reconhecidas na sociedade em diferentes áreas. As características não apontavam a cor da pele, etnia, nem aspectos físicos, como explicitado abaixo:

Quadro 1: perfis

1. Ator, apresentador, diretor, escritor, entrevistador. Coleciona mais de 50 nomeações por conta dos diversos papéis acumulados em seu currículo. Das 50, venceu 30. 2. Atriz, formada em jornalismo. Já foi eleita pela Revista People como um dos rostos mais bonitos do mundo.

3. Ex-presidente dos EUA. Coleciona revistas do homem-aranha. Leu todos os livros do Harry Potter. Tem um par de luvas de boxe autografadas por Muhammad Ali. 4. Socióloga, política, feminista e defensora dos direitos humanos. Nascida e criada na maré. 5. Cantora. Ganhou 20 prêmios Grammy e é a mulher mais indicada da história do prêmio. Em setembro de 2010 ela foi nomeada a mulher mais bonita do mundo pela Revista People.

6. Cantora, compositora, atriz, modelo, fashion designer, produtora executiva, empresária e filantropa. Foi a primeira cantora no mundo a lançar um álbum com encarte em braile.

7. Jornalista, praticante de ioga e pilates. Ama macarrão instantâneo (miojo) e dançar quando está sozinha em casa.

8. Escritor. Um dos fundadores da Academia Brasileira de Letras. Era enxadrista e participou do primeiro campeonato brasileiro do esporte mental, ficando em terceiro lugar. 9. Pastor, teólogo, revolucionário, pacifista. Fumava em segredo. O homem mais novo a ser honrado com um Nobel da Paz. 


\section{RevistAleph}

10. Escritora, poetisa, romancista e ensaísta. Suas obras, abordam temas como a discriminação racial, de gênero e de classe.

11. Cantora, começou a cantar no coral da igreja. Foi descoberta fazendo covers no Youtube. Foi indicada ao Grammy Latino.

Fonte: Elaborado pelas autoras com base em informações de domínio público na internet.

Em um segundo momento, ainda nos pequenos grupos, eles deveriam identificar quem eram os 11 perfis. Ao finalizarem as atividades, foram exibidas as fotos dos perfis todos eles de pessoas negras famosas - no intuito de instigar o debate dentro dos grupos. A presença de um integrante do LEPIDEFE em cada pequeno grupo teria a função de mediar e problematizar as questões emergentes dessa discussão.

Em um terceiro momento, todos os participantes formaram uma grande roda de conversa para compartilharem tudo que foi debatido dentro dos pequenos grupos. Em seguida, houve um momento de reflexão sobre como combater o racismo e se era possível acabar com ele, e a finalização do evento.

\section{Relatando a experiência: dores e aprendizados}

Educar e educar-se, na prática da liberdade, não é estender algo desde a "sede do saber" até a "sede da ignorância" para "salvar", com este saber, os que habitam nesta. Ao contrário, educar e educar-se, na prática da liberdade, é tarefa daqueles que sabem que pouco sabem - por isso sabem que sabem algo e podem assim chegar a saber mais - em diálogo com aqueles que, quase sempre, pensam que nada sabem, para que estes, transformando seu pensar que nada sabem em saber que pouco sabem, possam igualmente saber mais (FREIRE, 1992, p. 16).

A partir das discussões, observamos pontos convergentes e divergentes tendo em vista as experiências nas duas escolas. Com relação aos pontos convergentes, ou seja, o que aconteceu em comum nas duas escolas, nenhum estudante prontamente relacionou o documentário sobre racismo com a dinâmica, mesmo tendo sido apresentado o assunto antes da exibição e o próprio curta ser explícito quanto ao tema. Nesse sentido, Munanga (2004, p.28) afirma que:

No Brasil, o mito de democracia racial bloqueou durante muitos anos o debate nacional sobre as políticas de "ação afirmativa" e paralelamente o mito do sincretismo cultural ou da cultura mestiça (nacional) atrasou também o debate nacional sobre a implantação do multiculturalismo no sistema educacional brasileiro. 


\section{RevistAleph}

A invisibilidade do tema racismo ou mesmo de não valorização da negritude nas escolas é preocupante e ainda bastante comum. Daí a importância de se ampliar o debate para que mais facilmente os estudantes identifiquem essa questão como primordial de ser debatida e sobretudo de estar presente cotidianamente na vida escolar e na sociedade como um todo, não somente em eventos pontuais.

O distanciamento do tema ficou evidente no segundo momento da dinâmica, quando os estudantes deveriam identificar quem eram as pessoas retratadas nos perfis, e, em ambas as escolas, os estudantes mencionaram majoritariamente pessoas brancas (Ex: Leonardo DiCaprio, Jô Soares, Tatá Werneck, Fátima Bernardes, Anitta, Pedro Bial, Fernanda Gentil, Thalita Rebouças, Malala, Silas Malafaia, Padre Fábio de Melo).

Referenciando diversos autores desse campo, Santos e Silva (2018, p. 256), apontam que a partir da metade do século XIX, as teorias raciais baseavam-se no chamado racismo científico, afirmando "a ideia de que a humanidade está dividida em raças, e seu corolário, a saber, as diferentes raças conformam uma hierarquia biológica, na qual os brancos ocupam posição superior" Ainda hoje vemos reflexos dessa influência com muitas referências de pessoas brancas em destaque na mídia e na sociedade, em detrimento das aparições de pessoas pardas e pretas. Há que se refletir como essas pessoas são representadas.

Acevedo, Nohara, Ramuski (2010), apoiadas em diversos estudos sobre as relações raciais, questionam as representações dos negros na mídia em comparação com sua proporção na população e ainda assim quando aparecem, são sub-representados, ressaltando ainda os discursos carregados de ideologias racistas. Não bastasse a pouca representatividade na mídia, as pessoas negras são apresentadas com vestimentas simples, em profissões subalternas, sozinhos ou com outros negros majoritariamente, possuem papéis secundários ou de figurantes, estereotipados comumente como criminosos, favelados ou prostitutas.

No contexto do cinema, Rodrigues (2001) relacionou vários estereótipos, como o escravo, o preto velho, o mártir, o nobre selvagem, o negro revoltado e o crioulo doido. Em pesquisas sobre telenovela, Araújo (2004) menciona a mãe negra, o serviçal bonzinho, a negrinha infantilizada, o anjo da guarda, o negrinho endiabrado, o amigo do herói branco, o negro de alma branca, o malandro carioca, entre outros. De modo geral, os estereótipos são marcados por traços de sensualidade, erotismo, criminalidade e feiura (Chinellato, 1996; Da Silva \& Rosemberg, 2008; Pinto, 1987); (ACEVEDO, NOHARA, RAMUSKI, 2010, p. 63). 


\section{RevistAleph}

Inevitavelmente esse desequilíbrio de poder e de condição econômica e social na interação entre brancos e negros reforça o racismo. Com essa forte influência do cinema e especialmente das novelas e dos comerciais de televisão, que acessa mais as pessoas, qual referência tem jovens negros? Como se reconhecem?

Poucos estudantes citaram pessoas negras durante a dinâmica, porém os dois perfis mais citados foram do Ex-Presidente dos Estados Unidos da América Barack Obama e da Vereadora brutalmente assassinada Marielle Franco, talvez pela descrição dos perfis com informações mais difundidas na mídia. Porém, mesmo este fato não contribuiu como pista para identificar que se tratava de uma dinâmica com todos os perfil de pessoas negras e que a discussão central era sobre o combate ao racismo.

Ainda em comum foi a surpresa de todos os estudantes ao mostrarmos quem eram de fato as pessoas cujos perfis foram expostos e eles constatarem que eram todos pessoas negras.

Quadro 2: Perfis revelados

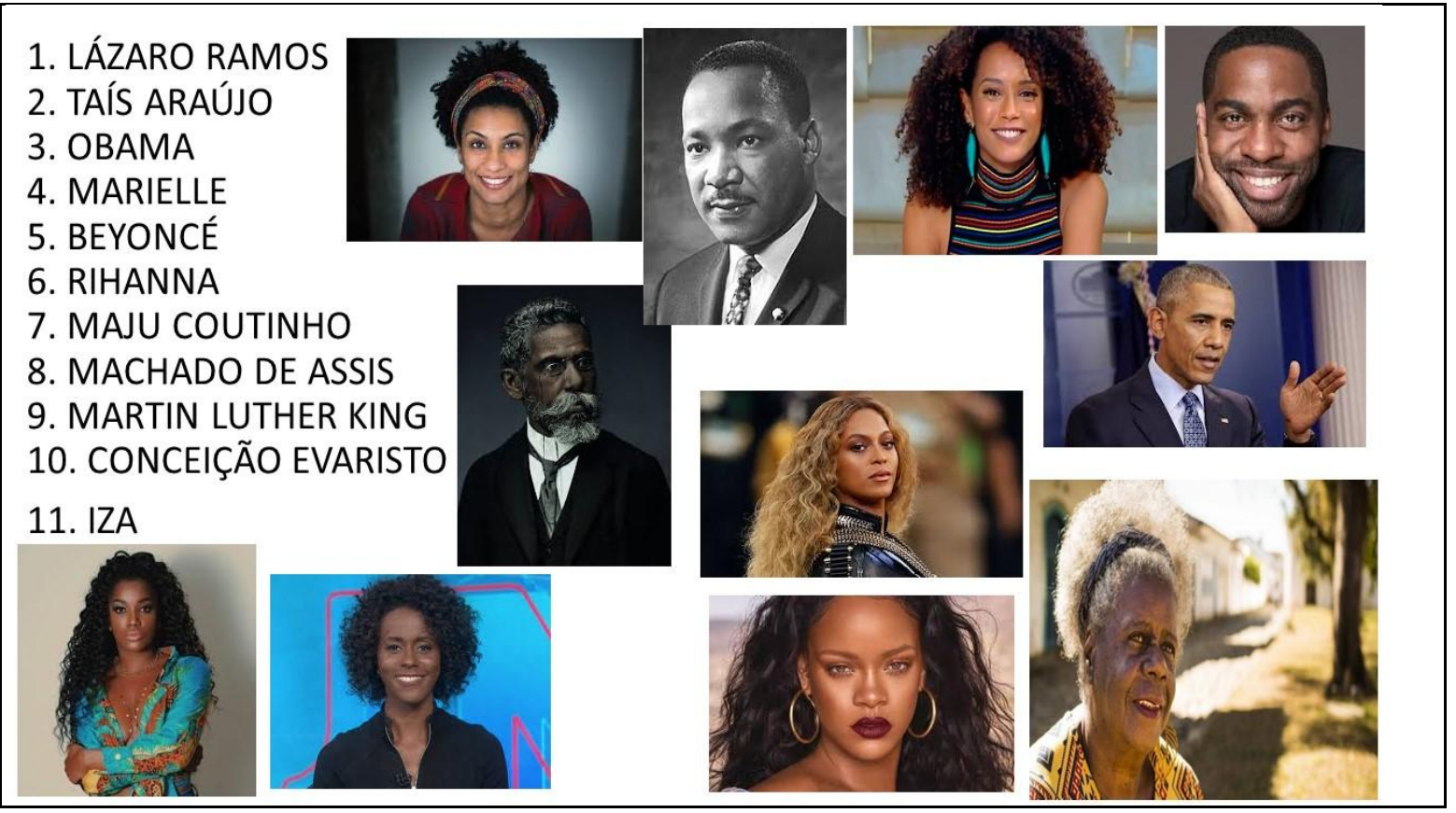

Fonte: Elaborado pelas autoras com base em fotos de domínio público na internet.

É preciso problematizarmos essa questão e refletirmos, por exemplo, por que o perfil de Lázaro Ramos foi confundido com Pedro Bial, Leonardo DiCaprio e Jô Soares? O de Taís Araújo com Tatá Werneck e Patrícia Poeta? O de Maju Coutinho com Fátima Bernardes e Fernanda Gentil? O de Iza com Anitta? O de Martin Luther King com Silas Malafaia e Padre 


\title{
RevistAleph
}

Fábio de Melo? O de Beyoncé com Lady Gaga e Katy Perry. O de Conceição Evaristo com Thalita Rebouças e Malala?

Isso exemplifica tal questionamento, pois há uma notória invisibilidade com relação aos feitos de pessoas negras comparado à supremacia branca como referência desses jovens que participaram desse estudo.

\begin{abstract}
A sociedade brasileira "apenas" reproduz o modelo de beleza "ideal" branca que está estampada nas revistas, novelas, no cinema e em todos os meios predominantes de comunicação. Essa reprodução internaliza nas crianças uma "suposta superioridade" da raça branca. Num primeiro momento essa prática não aparenta perigo, mas, com o passar dos anos ela poderá prejudicar seriamente o processo de socialização desse jovem negro a ponto de muitos deles tentarem negar a sua própria raça (ARAÚJO, 2012, p. 534).
\end{abstract}

Em ambas escolas, notamos um melindre inicial em se autodeclararem negros ao longo dos debates. Alguns se intitulavam como "morenos", "escurinhos" e muitos falavam sobre a cor do outro colega, mas dificilmente se autodeclaravam pretos ou pardos, especialmente no início dos debates.

Como mostrado no quadro acima, intencionalmente escolhemos personalidades negras com diferentes características com relação a gênero, idade, profissão, tipo de cabelo, tom da pele e nacionalidade para que pudéssemos possibilitar reflexões sobre as diferentes formas de se negro e assim provocar uma identificação com os perfis.

Fernandes e Souza (2016) apontam para reflexões envolvendo o processo de alienação dos negros brasileiros, sendo levados muitas vezes a negação ou a repulsa do seu próprio corpo, da sua condição e da sua história ancestral, "enveredando-se em um processo de autodestruição que se inicia pelo "apagamento" de marcas físicas (branqueamento físico, mutilações, entre outros) e psíquicas (negação de sua condição física de negro)" (p.112). Nesse sentido, a questão do estigma é central de ser problematizada, como uma forte rejeição de características pessoais, que geram marcas de desvalorização social a ponto de se autodenominar com palavras que minimizam ou escamoteiam ser negro. Este estigma, imposto socialmente, "impede o negro de desenvolver um sentimento de pertencimento racial e, paralelamente, de construir a autoestima baseada numa identidade racial positiva". (p.112).

Outro ponto em comum, ainda durante os debates em pequenos grupos, foi a exposição de situações racistas vivenciadas ou presenciadas, dentro e fora da escola, pelos 


\title{
RevistAleph
}

estudantes. Nos relatos de ambas as escolas, uma grande loja de departamentos, shoppings e transportes públicos foram citados como locais que aconteceram perseguições de estudantes negros associadas a vestimentas, o uso do uniforme de escola pública ou chinelo.

\begin{abstract}
"Eu tava no shopping de havaiana branca...eu comprei uma havaiana só pra ir pro shopping! Tava com roupa normal, carteira e celular no bolso...aí uma moça passou, me olhou e virou pros filhos e pro marido e disse 'não fica perto dessa garota não porque ela é preta, ela pode roubar nosso celular" "(Estudante da escola da zona sul).
\end{abstract}

"Aconteceu esses tempos, todo mundo aqui sabe, tava todo mundo junto...um grupo 7,8 pessoas foi junto pegar o ônibus e teve um moço que parou um amigo nosso só por ele ser o mais "escurinho" e ele acabou batendo nele...acabou acontecendo só porque ele era mais "escuro", sendo que o rapaz também era negro!" (Estudante da escola na zona sul).

"Professora, só porque tínhamos entrado pela porta de trás no ônibus, com uniforme escolar e por ser preto, alguns passageiros mandaram a gente descer, e mesmo falando que só estávamos querendo ir pra casa, um deles levantou e deu tapa na cara do meu amigo e assim acabamos sendo obrigados a descer e esperar o próximo ônibus" (Estudante, com olhos lacrimejando, da escola da zona norte).

"Porque a sociedade já tornou isso natural!" (Estudante da escola da zona norte).

O preconceito se apresenta de diversas formas e vem de diversas partes, de brancos e de negros. A não discussão sobre esse tema faz com que essa causa seja invisibilizada e não problematizada pelos próprios negros, que também podem se configurar como opressores.

As consequências da ideologia do branqueamento para o negro foram bastante nefastas, como a recusa de sua própria aparência, a negação de sua ancestralidade, forte sentimento de inferioridade e autoimagem negativa. Quanto mais profundos os traumas do racismo, mais o negro ajustava seu comportamento e atitudes à ideologia do branqueamento, e quanto maiores eram os ataques racistas, mais profundos eram os traumas. A peculiaridade dessa ideologia foi transformar o discriminado em agente reprodutor do discurso discriminatório, colocando o negro a serviço de uma pátria racista (Domingues, 2002; Seyeferth, 1993); (ACEVEDO, NOHARA, RAMUSKI, 2010, p.62).

Paulo Freire (1994, p.21), ao afirmar que "os oprimidos, em lugar de buscar a libertação, na luta e por ela, tendem a ser opressores também", já anunciava a importância da educação como um instrumento dialógico que estimule o oprimido à emancipação, 


\section{RevistAleph}

encerrando as opressões porque passam e que estão presentes na sociedade. Nesse sentido, nossa ação pedagógica se apoia na intenção da dialogicidade nas propostas de uma educação antirracista. A extensão nos permite essa dialogicidade, com um protagonismo de todos os atores sociais envolvidos: os estudantes da educação básica, professores em formação e já formados falando sobre suas percepções e angústias. "Nesta teoria da ação, exatamente porque é revolucionária, não é possível falar nem em ator, no singular, nem apenas em atores, no plural, mas em atores em intersubjetividade, em intercomunicação" (FREIRE, 1994, p.80).

Os casos relatados dentro da escola envolviam atitudes dos próprios estudantes, e de professores também. Também foram recorrentes as falas afirmando que não era comum discutirem sobre esse tema durante as aulas, e muitas vezes, quando casos de racismo aconteciam eram invisibilizados ou minimizados por colegas e professores.

\footnotetext{
"Aqui na escola também, um amigo, que se dizia amigo meu, ficava me chamando de "marrom-bombom", "negresco" que é um biscoito preto, me chamava de "negrito" que é uma fonte preta, ficava zoando meu cabelo e tal, porque ele era branco e tal" (Estudante da escola da zona norte).

"O racismo ainda acontece porque a gente não fala sobre isso na escola" (Estudante da escola na zona norte).

"A maioria dos professores não falam muito sobre isso, não se envolvem não...acho que nem reparam" (Estudante da escola na zona sul).
}

Reconhecemos que o tema racismo é muito complexo de ser tratado pedagogicamente, até pelas lacunas na formação docente nesse campo, porém é inadmissível a sua invisibilidade, posto que casos como esses narrados acontecem cotidianamente não só com os estudantes dessas escolas, mas infelizmente com frequência na sociedade. A forma de combatermos esses casos é incentivarmos e atuarmos para a construção de uma educação antirracista, permeando todas as disciplinas, todos os espaços escolares, toda trajetória formativa dos estudantes da educação básica, da formação inicial e continuada docente e da formação.

A lei 11.645, de 10 março de 2008 (BRASIL, 2008) altera a Lei 9.394, de 20 de dezembro de 1996, modificada pela Lei 10.639, de 9 de janeiro de 2003, e estabelece as diretrizes e bases da educação nacional para incluir no currículo oficial da rede de ensino a obrigatoriedade da temática História e Cultura Afro-Brasileira e Indígena. Leis como essa intencionam que a sociedade reconheça a história e as contribuições desses povos, que 


\section{RevistAleph}

muitas vezes ainda são depreciadas, perpetuando assim o preconceito e exclusão. Esse é um grande avanço, porém, somente a legislação ou a política pública não são suficientes.

Não existem leis no mundo que sejam capazes de erradicar as atitudes preconceituosas existentes nas cabeças das pessoas, atitudes essas provenientes dos sistemas culturais de todas as sociedades humanas. No entanto, cremos que a educação é capaz de oferecer tanto aos jovens como aos adultos a possibilidade de questionar e desconstruir os mitos de superioridade e inferioridade entre grupos humanos que foram introjetados neles pela cultura racista na qual foram socializados (MUNANGA, 2005, p.17).

Para que essas ações afirmativas estejam de fato presentes na educação brasileira, é importante não só contemplarem a educação básica mas também a formação de professores, de modo a incentivar esse círculo virtuoso de formação crítica, inclusiva e historicamente democrática.

Ressaltamos que esses primeiros relatos dos estudantes surgiram ainda nas discussões nos pequenos grupos focais, e foi muito recorrente dizerem-se constrangidos de contar essas histórias. Com a mediação dos integrantes do LEPIDEFE, professores em formação, eles foram se sentindo mais à vontade para relatar situações muito ofensivas que os afligem diretamente ou a alguém muito próximo. Gomes (2005) aponta dois lados para o racismo, um envolve a aversão ou ódio às pessoas com pertencimento racial considerando características físicas observáveis "tais como: cor da pele, tipo de cabelo, etc", a outra envolve "um conjunto de ideias e imagens referente aos grupos humanos que acreditam na existência de raças superiores e inferiores" (p. 52).

"Se o branco sente dor, o preto também sente, nós somos todos iguais" (Estudante da escola na zona norte).

"É difícil falar neste assunto, pois, só em ser preto e morar em favela todos já te olham diferente" (Estudante da escola na zona norte).

"Sempre alguém vai falar mal de você, sempre alguém vai ficar te criticando pelo que você é" (Estudante da escola na zona sul).

"Já levei dois tapas na cara da polícia [...]As pessoas que falam acham que não machuca, mas machuca a pessoa que ouve" (Estudante da escola na zona sul).

Acreditamos que essa estratégia de começar uma discussão tão pungente em grupos menores foi acertada, pois em ambas escolas houve casos de estudantes que se 


\section{RevistAleph}

sentiram tão emocionalmente abalados que saíram chorando do local. Obviamente foram acolhidos por nós, os acalmamos e eles por livre e espontânea vontade desejaram voltar ao evento e continuar as discussões. Porém, os relatos nos fazem refletir sobre o quanto o racismo fere e magoa, como mostra esse diálogo:

"-Por que você está chorando, Pedro"?

-Porque dói, professora, dói muito ver que alguém te xinga, acha que você vai roubar, só porque você é preto e pobre" (Estudante da escola na zona norte).

"Eu não ia roubar nada, só tava vendo os doces..." (Estudante da escola na zona sul).

Em comum nesses relatos está a associação da negritude, da classe social e do delito, um preconceito perigoso e flagrante, com raízes profundamente sistêmicas, conforme assinala Lima (2004, p.61), "numa sociedade em que, historicamente, o comportamento daqueles que vivem na pobreza é criminalizado - e os negros são, demograficamente, mais numerosos entre os pobres, eles acabam por ser duplamente discriminados". Além disso, esse choro demonstra a angústia e o sofrimento porque passam essas pessoas cotidianamente, num país que infelizmente ainda vive sob a égide do 'mito da democracia racial', que escamoteia essas dores.

Não basta apenas falar. É importante saber como se fala, ter a compreensão do que se fala e mais: partir para a ação, para a construção de práticas e estratégias de superação do racismo e da desigualdade racial. Essa é uma tarefa cidadã de toda a sociedade brasileira e não só dos negros ou do movimento negro. E a nossa ação como educadores e educadoras, do ensino fundamental à Universidade, é de fundamental importância para a construção de uma sociedade mais justa e democrática, que repudie qualquer tipo de discriminação (GOMES, 2005, p. 52).

Em comum, também percebemos relatos considerando a importância de ter maior representatividade negra na mídia, maior discussão sobre racismo na escola, além de questões levantadas pelos próprios participantes: O que é preciso fazer para combater o racismo? Qual papel da escola e da sociedade?

"Tratar as pessoas com mais igualdade" (Estudante da escola na zona norte).

\footnotetext{
${ }^{24}$ Nome fictício para preservar a identidade do estudante. 


\section{RevistAleph}

"Ter mais aulas como essa nas escolas" (Estudante da escola na zona norte).

"Temos que falar mais sobre isso, é muito importante" (Estudante da escola na zona sul).

"Ter mais pessoa negra sendo protagonista na novela e cinema. Geralmente, nos filmes, os protagonistas são brancos, até tem pessoas negras mas geralmente são menosprezadas, como a garçonete, a faxineira e outras profissões que são menosprezadas pela sociedade" (Estudante da escola na zona sul).

“O racismo, embora negado no discurso, é confirmado cotidianamente, na prática de nossas escolas. É impressionante como, além da simples omissão, o recurso que mais se adota para a questão racial é o silêncio." (FOSTER, 2004, p. 9). Isto posto, é importante reafirmar a necessidade de se construir e fortalecer práticas pedagógicas mais inclusivas que se distanciem sobremaneira do silenciamento, da invisibilidade e da opressão. Esta tarefa, com uma nova postura diante da questão racial, é de educadores e educadoras comprometidos com estreito diálogo com as necessidades e anseios sociais, tendo como porta vozes, os estudantes e suas experiências.

Com relação aos pontos divergentes que emergiram a partir das experiências nas duas escolas, ressaltamos inicialmente a questão do acesso à informação e à cultura. Percebemos isso, quando, por exemplo, os estudantes da escola municipal localizada no Leblon (Zona Sul do Rio de Janeiro) identificaram, depois de muito debaterem, os perfis de Conceição Evaristo, Martin Luther King e Machado de Assis; o que não ocorreu na escola municipal no Jardim Guanabara, Ilha do Governador (Zona Norte do Rio de Janeiro), pois sequer foram mencionados.

Isso nos levou a refletir sobre a influência que o acesso aos bens culturais exerce sobre a formação desses estudantes em bairros distintos. Ao longo do debate, os estudantes da escola na zona sul relataram que repetidas vezes frequentam bibliotecas e teatros públicos no entorno do bairro, além disso, a escola se situa no mesmo terreno do Núcleo de artes da prefeitura do Rio de Janeiro. Ficou evidenciado um acesso maior comparado aos estudantes da zona norte. É de suma importância para formação cidadã e crítica dos estudantes estar imerso ativamente no processo de conhecimento e valorização das artes e dos bens culturais de forma geral, mas especificamente nesse caso em tela a cultura africana e afro-brasileira, com próxima articulação com os conteúdos escolares. 


\title{
RevistAleph
}

Outros pontos divergentes foram percebidos a partir da abertura do debate na grande roda de conversa com a participação de todos os presentes. Na escola localizada na zona norte, percebemos que os estudantes brancos se posicionaram mais na defesa de uma desconstrução de padrão de beleza, representatividade e estereótipos hegemonicamente brancos.

\begin{abstract}
"Normalmente o padrão de beleza de uma modelo na sociedade é branca, loira, olhos claros, cabelo liso. (Estudante da escola na zona norte).

"Eu acho que pelo fato da pessoa ser branca, é mais fácil pra conseguir arrumar um trabalho do que uma pessoa negra" (Estudante da escola na zona norte).
\end{abstract}

"Então não faz o menor sentido! (...) A pessoa pode ser o que ela quiser, independente da sua cor, mas a sociedade quer impor, quer colocar na nossa cabeça que existe esse padrão de beleza que a gente tem que seguir. Mas pra mim, eu acho que tá errado isso" (Estudante da escola na zona norte).

"Se você pegar um grupo de pessoas e botar uma pessoa negra e uma pessoa branca, e perguntar o que a pessoa negra vai ser, a maioria vai responder: vai ser faxineira, bandido, ladrão...as únicas opções que o negro vai ter. Aí chega no branco: doutor, advogado, médico, dentista, professor, empresário...isso é o que a sociedade impõe" (Estudante da escola na zona norte).

A luta antirracista deve ser de todas as pessoas, e não somente das pessoas negras, mas essas falas acima elencadas nos impressionaram pois partiram de estudantes brancos e os estudantes negros silenciaram inicialmente, talvez pela dor que sentem ao falar sobre essas experiências muito impactantes em suas vidas.

A educação antirracista é uma necessidade premente para todos, mas principalmente para dar ciência às pessoas negras de uma história ancestral que pouco se conhece, e que muitas vezes é contada de modo bastante depreciativo. Exatamente por isso, é fundamental ter consciência histórica para resgatar "[...] o fio condutor da verdadeira história do Negro que o liga sem distorções e falsificações" (MUNANGA, 2012, p.9). Assim, incentivar a fala e o protagonismo negro, bem como sua autoestima e autoconfiança para abertamente debater sobre suas dores e conquistas é fundamental.

Uma vez cristalizadas e difundidas no ambiente escolar, estas construções preconceituosas são internalizadas e legitimadas, deturpando a formação de negros e brancos. Embora a discriminação e o preconceito atinjam a negros e brancos, e a questão da formação na cultura africana e afro- 


\title{
RevistAleph
}

brasileira não seja interesse apenas dos negros, é preciso notar que o impacto da discriminação é diferenciado para aquele que discrimina e para aquele que é discriminado (FERNANDES E SOUZA, 2016, p.113).

$\mathrm{Na}$ escola localizada na zona sul, os/as estudantes negros/as participaram mais das discussões da grande roda de conversa. Passado o período inicial de timidez ao se pronunciar, notamos que nesta escola os estudantes negros se posicionaram mais. A estudante negra que abriu a discussão se utilizou da citação de Martin Luther King para dizer que atitudes racistas ainda acontecem porque nós ainda não aprendemos a conviver coletivamente:

\footnotetext{
"Aprendemos a voar como os pássaros, e a nadar como os peixes, mas ainda não aprendemos a simples arte de viver como irmãos" (Estudante da escola na zona sul).
}

Um estudante apontou a questão da desigualdade racial presente nas escolas públicas e privadas, e convidou os colegas a refletirem sobre essa questão.

\begin{abstract}
"Queria falar da exclusão e da desigualdade racial presente nas escolas públicas e privadas. Eu estudei numa escola particular que de tarde estudava quem era bolsista, ali estavam os negros, e de manhã quem pagava, então a maioria era branca...aqui (na escola pública) não tem isso, é totalmente diferente, mas eu queria que vocês parassem pra reparar isso, o quão desigual é" (Estudante da escola na zona sul).
\end{abstract}

De acordo com dados do IBGE $^{25}$ Pesquisa Nacional por Amostra de Domicílios (PNAD), 2018, no âmbito do ensino fundamental na educação pública, num total de 22.769 estudantes, há majoritariamente pretos ou pardos (64,9\%) em relação aos brancos $(34,3 \%)$; já na educação privada, num total de 4.880 estudantes, a maioria é branca $(56,9 \%)$ e 41,8\% são pretos ou pardos.

Esses dados nos mostram que, quantitativamente há mais negros na rede pública do que na rede privada, o que corrobora a fala do estudante acima mencionado. Em que pese toda discussão envolvendo classe social e raça, a percepção do estudante sobre exclusão e desigualdade deve ser considerada, pois segundo Sawaia (2017) "a dialética inclusão/exclusão gesta subjetividades específicas que vão desde o sentir-se incluído ao sentir-se discriminado ou revoltado" (p.9). A citada autora ainda esclarece que a exclusão,

25 Instituto Brasileiro de Geografia e Estatística. Disponível em: https://www.ibge.gov.br/estatisticas/sociais/populacao/25844-desigualdades-sociais-por-cor-ouraca.html?=\&t=resultados. Total de estudantes em números absolutos (1000 pessoas). 


\title{
RevistAleph
}

como um processo complexo e multifacetado, se apresenta sob diferentes prismas considerando aspectos materiais, políticos, relacionais e subjetivos, envolvendo as relações entre os indivíduos, os afetando concretamente causando dor e sofrimento, porém, "esse sofrimento não tem a gênese nele, e, sim, em intersubjetividades delineadas socialmente" (ibdem, p. 99).

Na escola da zona sul, ao final de toda discussão, um professor de Português negro pediu para se pronunciar e fez uma fala emblemática a respeito de tudo que foi discutido.

\begin{abstract}
"Sobre o tema... discussão extremamente fundamental para nossas vidas! Lembrando que pessoas perdem vida muitas vezes por não discutirem, por não ter consciência do que nós estamos falando aqui. Você tem consciência de quem você é? Sem se reconhecer, a gente muitas vezes não se percebe alvo da maldade que estão fazendo com a gente. Muitas vezes a gente acha que esse negócio de racismo é bobeira porque primeiro: a gente sequer se reconhece como negros. Há uma dificuldade muito grande dos próprios negros se reconhecerem como negros. Às vezes a gente sabe da história familiar, conhece os pais, vê os traços físicos, mas a pessoa diz "eu sou morena" ou "eu sou moreno". Essa negação de si mesmo faz parte de um processo maior, que é um processo de tentar fazer com que você não lute por aquilo que você é. Um processo que é orquestrado para continuar mantendo as coisas do jeito que estão, e como que é que as coisas estão? Vocês falaram aqui. $O$ nosso amigo falou das diferenças sociais, que estão misturadas com as diferenças étnico-raciais. As meninas falaram do que já passaram, do que já sofreram, mas o maior ato de libertação que a gente pode ter é reconhecendo a nossa história. E a nossa história não é uma história de um povo oprimido, a nossa história é de um povo que se superou. A nossa história não é uma história de escravos, é de um povo que se libertou" [...](Professor da escola da zona sul).
\end{abstract}

Este depoimento é bastante impactante e necessário. Conhecer essas histórias e reconhecer o quanto de desrespeito, abuso e discriminação racial há nisso é um passo decisivo para refletir sobre o lugar do negro na sociedade e também no âmbito escolar. A representatividade importa muito ao confrontarmos o racismo estrutural. A importância de docentes negros com consciência do seu papel social nas instituições de ensino é fundamental posto que, os estudantes se sentirão representados, inspirados a agregar mais experiências e mais discussões. Nesse sentido, Gomes (2003, p.171) nos instiga a refletir: "Construir uma identidade negra positiva em uma sociedade que, historicamente, ensina ao negro, desde muito cedo, que para ser aceito é preciso negar-se a si mesmo, é um desafio enfrentado pelos negros brasileiros. Será que, na escola, estamos atentos a essa questão?" 


\section{RevistAleph}

"E isso não é "mimimi", inclusive eu odeio essa expressão. Só usam a expressão "mimimi" pra falar sobre a luta dos negros, a luta das mulheres, a luta das questões homoafetivas, tudo que é luta por igualdade, chamam de "mimimi". E não é uma coisa inútil, porque é uma coisa que está no dia a dia de vocês. Quantos de vocês já não levaram tapa na cara de policial? Eu já levei tapa na cara de policial, mais de uma vez. Vocês conhecem as minhas histórias...de estar em carro meu, comprado, e um policial perguntar de quem eu tinha roubado o meu carro, isso enquanto me batia. Essa é uma das histórias. Então isso é uma coisa que vai nos acompanhar por muito tempo, pelo resto das nossas vidas" (Professor da escola da zona sul).

Almeida (2018, p. 59) nos faz refletir sobre as estruturas racistas enraizadas na sociedade, como por exemplo, ao "considerar ofensas raciais como 'piadas', como parte de um suposto espírito irreverente que grassa na cultura popular em virtude da democracia racial". A desvalorização da ofensa, da dor e do sofrimento que estão envolvidos os casos de racismo ou injúria racial, naturaliza e aprofunda as discriminações.

É necessária uma profunda reflexão sobre o racismo estrutural que estamos imersos para entender os modos de organização da sociedade, e como o racismo opera do micro ao macro. Por isso, é tarefa de todos nós a luta por uma sociedade em que as pessoas possam conviver em liberdade, terem seus direitos respeitados igualitariamente, com consciência social e crítica, e não esmorecer frente aos retrocessos.

\section{Considerações finais}

Ao acreditarmos na potência da extensão universitária, seguimos os ensinamentos de Paulo Freire (1994), no sentido das teorias de ação dialógica e portanto, revolucionáriolibertadora, distanciando-se absolutamente da ação antidialógica e opressora.

Este artigo, que teve como objetivo analisar a experiência do evento de extensão $7^{\circ}$ Ciclo de Cinema e Diversidade em duas Escolas Municipais do Rio de Janeiro, propôs socializar nossas reflexões coletivas sobre um tema ainda muito negligenciado no campo escolar e na sociedade como um todo.

Em consonância com o título do documentário "ninguém nasce assim", ninguém nasce racista. A ressignificação e a desconstrução são necessárias. A nossa luta coletiva por uma educação antirracista só será efetivada se, no lugar de silenciamentos, omissões, opressões e dores, promovermos ações pedagógicas inclusivas, reflexivas e participativas, para que os privilégios sejam repensados e os preconceitos sejam eliminados. 


\section{RevistAleph}

Como nos apoiamos no conceito de inclusão de forma ampla, considerando-o como um processo dialético e infindável, esse trabalho nos mostra que a operacionalização desse conceito atinge a todas as pessoas envolvidas e não somente um público específico. Justamente por isso, pensamos ser importante socializarmos essas experiências pedagógicas, extensionistas e inclusivas em desejoso e permanente diálogo da universidade com a sociedade.

Esse é um tema pertinente a Educação, a Educação Física escolar, a todas as disciplinas e espaços escolares que se inquietam em formar para o diálogo, para o acolhimento e respeito às diferenças e que acreditam nos desdobramentos dessas reflexões na vida social de todos os envolvidos, numa rede que é tecida a várias mãos considerando a perspectiva inclusiva e participativa.

A aproximação da universidade com a escola propõe ressignificar o compartilhamento de saberes não hierarquizados, além de fortalecer a luta intransigente pela educação pública, gratuita, autônoma, crítica e democrática. Participar desta ação nos oportuniza não só impactar a realidade escolar, mas também a nossa formação enquanto professoras em constante reflexão e transformação, experienciando todos os desafios e possibilidades que a complexidade do âmbito escolar e social nos apresenta.

\section{Referências}

ACEVEDO, Claudia Rosa; NOHARA, Jouliana; RAMUSKI, Carmen Lídia. Relações raciais na mídia: um estudo no contexto brasileiro. Revista Psicologia Política. São Paulo, v. 10, n. 19, p. 57-73, jan. 2010.

ALMEIDA, Silvio Luiz de. O que é racismo estrutural?. Belo Horizonte: Letramento, 2018.

ARAÚJO, Ilze Arduini de; BERNARDES, Vânia Aparecida Martins. Discriminação racial em sala de aula, In: RODRIGUES FILHO, Guimes; BERNARDES, Vânia Aparecida Martins; NASCIMENTO, João Gabriel do. Educação para as relações étnico-raciais: outras perspectivas para o Brasil. Uberlândia: Editora Gráfica Lops, 2012. p. 523-540.

BOOTH, Tony; AINSCOW, Mel. Index Para a Inclusão. Desenvolvendo a aprendizagem e a participação na escola. Traduzido por: Mônica Pereira dos Santos. Produzido pelo LaPEADE, 2012.

BRASIL. Presidência da República. Lei n. 11.645, de 10 de março de 2008. Altera a Lei n. 9.394, de 20 de dezembro de 1996, modificada pela Lei n. 10.639, de 9 de janeiro de 2003, que estabelece as diretrizes e bases da educação nacional, para incluir no currículo oficial da rede de ensino a obrigatoriedade da temática "História e Cultura Afro-Brasileira e Indígena". Brasília, 2008. 


\section{RevistAleph}

FERNANDES, Viviane B., SOUZA, M. C. Identidade Negra: entre exclusão e liberdade. Revista do Instituto de Estudos Brasileiros. n. 63. abr. 2016 (p. 103-120)

FONSECA, Michele. Formação de professores de Educação Física e seus desdobramentos na perspectiva dos processos de inclusão/exclusão: reflexões sobre Brasil e Portugal. Tese de Doutorado. UFRJ, Rio de Janeiro, 2014.

FORPROEX. Política Nacional de Extensão Universitária. Gráfica da UFRGS. Porto Alegre, RS, 2012 (Coleção Extensão Universitária; v.7).

FOSTER, Eugenia da Luz Silva. Racismo e movimentos instituintes na escola. 2004. $148 \mathrm{f}$. Tese (Doutorado) - Departamento de Centro de Ciências Sociais e Aplicadas, Universidade Federal Fluminense, Niterói, 2004.

FREIRE, Paulo. Pedagogia do oprimido. 23ạ reimpressão. Rio de Janeiro: Paz e Terra, 1994

FREIRE, Paulo. Extensão ou Comunicação? 10 ed. Rio de Janeiro: Paz e Terra, 1992.

FREIRE, Paulo. A Educação na Cidade. 5. ed. São Paulo: Cortez, 2001.

FREIRE, Paulo. Pedagogia da Autonomia: saberes necessários à pratica educativa. 34a edição. São Paulo: Paz e Terra, 2006

GATTI, Bernadete. Grupo focal na pesquisa em ciências sociais e humanas. Brasília: Líber Livro, 2005.

GOMES, Nilma Lino. Educação, identidade negra e formação de professores/as: um olhar sobre o corpo negro e o cabelo crespo. Educação e Pesquisa, São Paulo, v.29, n.1, , jan./jun. 2003, p. 167182.

GOMES, Nilma Lino. Alguns termos e conceitos presentes no debate sobre relações raciais no Brasil: uma breve discussão. In: BRASIL. Educação anti-racista: caminhos abertos pela Lei Federal $n^{\circ}$.10.639/03. Secretaria de Educação Continuada, Alfabetização e Diversidade. - Brasília:

Ministério da Educação, Secretaria de Educação Continuada, Alfabetização e Diversidade, 2005, p. 39-62.

LIMA, Renato Sérgio de. Atributos raciais no funcionamento do sistema de justiça. São Paulo em perspectiva, 18(1), 2004. p.60-65.

MUNANGA, Kabengele. Uma abordagem conceitual das noções de raça, racismo, identidade e etnia. In: BRANDÃO, André Augusto (Org). Programa de educação sobre o negro na sociedade brasileira. Ed. UFF: Niterói-RJ, 2004.

MUNANGA, Kabengele. (Org). Superando o Racismo na escola. Brasília: Ministério da Educação, Secretaria de Educação Continuada, Alfabetização e Diversidade, 2005.

MUNANGA, Kabengele. Negritude: usos e sentidos. Belo Horizonte: Autêntica, 2012.

NOGUEIRA, Maria das Dores. Políticas de Extensão Universitária Brasileira. Belo Horizonte: Editora UFMG, 2005. 


\section{RevistAleph}

SANTOS, Mônica; FONSECA, Michele; MELO, Sandra. Inclusão em Educação: diferentes interfaces. Curitiba, CRV, 2009.

SANTOS, Raquel Amorim dos; SILVA, Rosângela Maria de Nazaré Barbosa e. Racismo científico no Brasil: um retrato racial do Brasil. Educar em Revista, Curitiba, Brasil, v. 34, n. 68, mar./abr. 2018, p. 253-268.

SAWAIA, Bader (Org.) As artimanhas da Exclusão: análise psicossocial e ética da desigualdade social. Petrópolis: Vozes, 2017.

SILVA, Ana Patrícia da. O princípio da Inclusão em Educação Física escolar: um estudo exploratório no município de São João Del Rei. Dissertação de Mestrado: Universidade Federal do Rio de Janeiro, 2004.

THIOLLENT, Michel. Metodologia da pesquisa-ação. 10. ed. São Paulo: Cortez; Autores Associados, 2000.

Data do envio: $11 / 04 / 2020$

Data do aceite: $06 / 05 / 2020$. 